DOI: https://doi.org/10.47405/mjssh.v5i7.436

\begin{tabular}{|c|c|}
\hline 1. 1.54 & Malaysian Journal of Social Sciences and Humanities (MJSSH) \\
\hline $\begin{array}{c}\text { Malaysian Journal of } \\
\text { solal sciences and }\end{array}$ & Volume 5, Issue 7, July 2020 \\
\hline (MJ-SSH) & e-ISSN : 2504-8562 \\
\hline & $\begin{array}{l}\text { Journal home page: } \\
\text { www.msocialsciences.com }\end{array}$ \\
\hline
\end{tabular}

\title{
Amalan Kemahiran Penyesuaian dalam kalangan Pelajar Universiti: Suatu Pemerhatian Awal
}

\author{
Nurul Haidah Saidon', Muhammad Ilham Ahmad Zaini', Muhammad Athif Asyraf Sukry', Mohamad \\ Izzuan Mohd Ishar ${ }^{2}$ \\ 1Fakulti Sains, Universiti Teknologi Malaysia (UTM) \\ ${ }^{2}$ Sekolah Pendidikan, Fakulti Sains Sosial dan Kemanusiaan, Universiti Teknologi Malaysia (UTM)
}

Correspondence: Muhammad Athif Asyraf Sukry (athifasyraf2@gmail.com)

\begin{abstract}
Abstrak
$\overline{\text { Dalam mengharungi kehidupan di peringkat pengajian tinggi, pelajar akan menghadapi perasaan yang }}$ bercampur baur seperti gelisah, gusar, takut, malah bercampur gembira dan teruja apabila ditawar dan diterima masuk ke kolej atau universiti. Pada semester pertama, keadaan mereka boleh menimbulkan rasa tertekan dan banyak penyesuaian yang perlu dilalui. Pelajar juga boleh rasa teruja untuk mempelajari perkara yang baru. Perasaan ini mendorong mereka untuk bersiap sedia menghadapi suasana pengajian yang jauh berbeza dari keadaan di sekolah. Ketika ini kemahiran penyesuaian digunakan untuk terus bertahan dan membiasakan diri dengan persekitaran baru. Selain kemahiran teknikal, graduan ideal yang berbakat juga mempunyai ciri-ciri kemahiran insaniah. Keazaman dalam membangunkan Kemahiran Insaniah pelajar telah menggerak Kementerian Pengajian Tinggi untuk menghasilkan Modul Pembangunan Kemahiran Insaniah sebagai rujukan kepada institusi pengajian tinggi di Malaysia. Penghasilan modul ini telah menyumbang kepada terciptanya atribut graduan untuk sesetengah universiti termasuk Universiti Teknologi Malaysia. Antara atribut graduan yang menyumbang kepada proses pengasahan kemahiran insaniah pelajar ialah kemahiran kesarjanaan, kemahiran berfikir, kemahiran kepimpinan, kemahiran keusahawanan dan kemahiran penyesuaian. Artikel ini merupakan artikel konsep yang membincangkan amalan yang boleh dipraktikkan oleh pelajar dalam menyesuaian diri dengan kehidupan di institusi pendidikan tinggi melalui interpersonal, intrapersonal dan kemudahan teknologi.
\end{abstract}

Kata kunci: kemahiran penyesuaian, atribut graduan, interpersonal, intrapersonal, teknologi

\section{Adaptability Skills Practices Among University Students: A Preliminary Observation}

\begin{abstract}
In the course of higher education, students will experience mixed emotions such as anxiety, anger, fear, and even happiness and excitement when being offered and accepted into college or university. In the first semester, their condition can be stressful and many adjustments need to be made. Students can also be excited to learn something new. This feeling prompted them to be prepared for the learning environment that was very different from the school setting. Currently, adaptability skills are used to survive and get used to the new environment. In addition to technical skills, talented ideal graduates also need to have soft skills. Determinants in the development of soft skills students have mobilized the Ministry of Higher Education to produce the Soft Skills Development Module about higher education
\end{abstract}


institutions in Malaysia. The production of this module has contributed to the creation of graduate attributes for some universities including Universiti Teknologi Malaysia. Among the graduate attributes that contribute to the student's soft skills process are scholarship skills, thinking skills, leadership skills, entrepreneurial skills and adaptability skills. This article is a concept article that discusses the students' practices in adapting to life in higher education institutions through interpersonal, intrapersonal, and technological facilities.

Keywords: adaptability skills, graduate attribute, interpersonal, intrapersonal, technology

\section{Pengenalan}

Sebilangan besar orang menjalani kehidupan yang harmoni di dunia ini tanpa memikirkan perkara lain. Namun, bagaimana jika peristiwa tidak diingini berlaku dan bagaimana orang menangani keadaan itu? Bagaimana jika harus tinggal di tempat yang sama sekali tidak biasa dan harus bertemu dengan orang baru?. Di sinilah kemahiran menyesuaikan diri digunakan untuk bertahan dan terbiasa dengan persekitaran baru. Kemahiran menyesuaikan diri ditakrifkan sebagai kemampuan untuk menyesuaikan diri dengan keadaan yang baru atau kemampuan untuk mengubah tingkah laku sekarang menjadi sesuatu yang baru dan sesuai untuk sesuatu situasi. Ia juga disebut sebagai adaptasi iaitu dari perkataan Inggeris yang telah diubah ke intonasi Melayu. Menurut Kamus Dewan Bahasa dan Pusataka edisi Kedua, adaptasi bermaksud proses evolusi di mana sesebuah populasi mampu menyesuaikan dirinya dengan persekitaran yang baru. Bertitik tolak dari persoalan diatas, artikel ini akan mengupas elemen kemahiran penyesuaian yang terdapat dalam atribut graduan yang boleh diamalkan oleh pelajar dalam menempuhi kehidupan di institusi pengajian. Tiga elemen kemahiran penyesuaian yang dihujahkan dalam artikel ini adalah elemen interpersonal, intrapersonal dan kemampuan menyesuaikan diri dengan teknologi.

\section{Elemen Kemahiran Penyesuaian}

\section{Penyesuaian Interpersonal}

Kaedah interpersonal adalah perkara yang berkaitan dengan cara yang diperlakukan terhadap orang lain. Terdapat banyak jenis kemahiran interpersonal yang baik seperti komunikasi, pengurusan konflik, dan empati terhadap orang lain. Kemahiran komunikasi adalah salah satu kemahiran interpersonal yang baik yang dapat digunakan oleh orang dalam kehidupan seharian mereka. Lolli (2013) menyatakan bahawa pengembangan kemahiran komunikasi penting untuk pelajar masa kini. Pelajar pada masa kini mempunyai perbezaan komunikasi yang berbeza kerana mereka dibentuk oleh teknologi. Seperti yang diketahui bahawa Generasi Milenium pada masa kini telah berkembang dengan teknologi dan mereka dilengkapi dengan media sosial maya seperti Facebook, Telegram, Twitter, dan banyak lagi yang membolehkan mereka berkomunikasi dengan orang lain. Komunikasi jenis ini akan memberi kesan apabila pelajar harus bekerja di tempat yang menggunakan komunikasi bersemuka. Ini menunjukkan bahawa adalah penting bagi seseorang untuk mempunyai kemahiran komunikasi agar dapat bertahan dalam situasi kehidupan sebenar. Berdasarkan artikel yang ditulis oleh Lolli (2013) juga, terdapat empat komponen utama komunikasi interpersonal termasuk mendengar, bahasa badan, bahasa verbal, dan tingkah laku. Komponen mendengar dan bahasa badan digunakan tanpa mengira nadanya. Terdapat beberapa contoh yang boleh dikaitkan dengan interpersonal seperti kemampuan untuk menghadirkan diri di hadapan orang lain, bercakap di khalayak, cara membalas ketika seseorang memberikan pandangan, dan banyak lagi. Komunikasi sangat penting dalam memahami dunia di sekeliling dan orang lain. Pelajar juga dapat membina hubungan dengan orang baru apabila komunikasi yang berkesan terjalin. Selain itu, pelajar dapat berkomunikasi dengan baik dengan semua orang apabila kita menghasilkan idea yang membina perbincangan. Penyelesaian konflik juga dapat dibuat apabila komunikasi berkesan berlaku. Kesimpulannya, komunikasi adalah penting untuk interpersonal kerana ia berperanan besar dalam kemahiran menyesuaikan diri. 
Pengurusan konflik pula bermaksud kemampuan untuk mengenal pasti, menangani, dan menyelesaikan masalah yang berlaku di persekitaran. Masalah akan berlaku di mana sahaja, sama ada di dalam organisasi atau ketika bertemu dengan orang baru. Menurut Nannan (2020), konflik antara individu adalah masalah umum tanpa mengira sistem. Antara sebab terjadinya konflik dalam industri ialah masalah tingkah laku, masalah kontrak, dan isu teknikal (Jaffar et al, 2011). Sekitar tahun 80-an, konflik juga dibincang oleh Robbins (1983) dan Sara (1986) dengan menyatakan bahawa jika konflik tidak dikendalikan dengan baik, ia akan mengakibatkan tingkah laku yang tidak diingini seperti persaingan yang tidak sihat, kecurigaan, ketidakpercayaan, gangguan terhadap pencapaian matlamat, dan produktiviti yang rendah oleh pandangan tradisional konflik. Oleh itu, pelajar perlu mempunyai kemampuan untuk mengurus konflik yang berlaku dalam persekitaran. Konflik tidak dapat dielakkan dan jika memilih untuk mengabaikannya, ia akan mengakibatkan masalah yang lebih besar. Oleh itu, pelajar harus menerima dan mencetuskan idea mengenai cara mengurus masalah. Sekiranya pelajar berada dalam organisasi dan menghadapi masalah, cara yang terbaik ialah bekerjasama dengan pasukan untuk menyelesaikannya dan bukannya menyalahkan pihak lain. Pelajar juga harus bersetuju untuk tidak bersetuju, yang bermaksud mempertimbangkan sudut pandang dan idea orang lain.

Seterusnya ialah empati terhadap orang lain yang boleh didefinisikan sebagai kemampuan untuk berkongsi perasaan orang lain dan membayangkan perasaan apabila berada dalam situasi seseorang. Main et. al. (2017) mendapati bahawa empati adalah sebahagian proses interpersonal. Empati interpersonal adalah perasaan prihatin tentang memperbaiki hubungan dengan orang lain. Maklum balas yang diberikan oleh orang yang bersikap empati, membantu untuk memberi kefahaman yang lebih mendalam mengenai hubungan persekitaran. Sebagai contoh, apabila rakan pelajar memberitahu bahawa dia mempunyai masalah pembelajaran, pelajar turut merasa gusar untuknya dan berharap bahawa rakannya dapat menyelesaikan masalah pembelajaran yang berlaku. Dalam situasi lain di mana rakan berada dalam masalah atau mempunyai masalah yang tidak dapat diselesaikan, pelajar meminjamkan telinga dan mendengar cerita rakannya dan merasa seperti berada di tempatnya. Itulah sebabnya mengapa empati penting untuk penyesuaian interpersonal kerana ia berperanan besar dalam memelihara hubungan dengan orang lain.

\section{Penyesuaian Intrapersonal}

Seterusnya, bahagian intrapersonal yang diperlukan untuk kita menyesuaikan diri dengan persekitaran baru kita. Kesesuaian di universiti bermaksud mampu berubah menjadi pelajar yang berjaya dan juga rakan baik kepada orang lain (Doyle, 2019). Kemampuan menyesuaikan diri adalah kemahiran insaniah penting yang perlu dimiliki oleh setiap orang sehingga akhir fasa pengajian. Bagi pelajar, jika seseorang yang cepat belajar, dia tahu bagaimana untuk menyesuaikan diri. Ia juga dapat meningkatkan lagi kemampuan penyesuaian dengan mencuba perkara baru dan mencabar kemampuan untuk menyelesaikan masalah dalam pelbagai keadaan, seterusnya kemahiran insaniah akan jauh lebih baik. Menerusi intrapersonal, ia hanya akan membincangkan tentang keyakinan diri, motivasi diri, dan kesedaran emosi.

Pertama sekali, salah satu kemahiran yang paling penting untuk intrapersonal adalah motivasi diri. Ini kerana memotivasikan diri untuk melakukan penilaian dan melakukan apa yang diperlukan berdasarkan keadaan akan menjamin kejayaan dalam hidup. Menurut The Life Virtue (2019), motivasi diri adalah kunci kejayaan yang harus dibawa ke mana sahaja. Ia juga akan membolehkan pelajar menambah baik diri terutama apabila menghadapi banyak kritikan sepanjang proses pengajian. Sekiranya ingin meningkatkan motivasi diri, apa yang perlu dilakukan ialah mencari petikan motivasi seperti "adakah itu mudah? Semestinya". Petikan sebegini akan membantu meningkatkan keyakinan dan membantu menjadi lebih bermotivasi terhadap tugas sebagai pelajar. Perkara seterusnya yang boleh dilakukan adalah pada waktu pagi, pergi ke hadapan cermin dan mengatakan kepada diri sendiri satu kata yang bercita-cita tinggi sebelum memulakan hari. Satu perkara yang perlu diingat, jika ingin membina keyakinan diri, pelajar harus mempraktikkan teknik-teknik yang dikongsi secara berterusan sehingga menyedari bagaimana satu kritikan orang lain akan memberi kesan baik pada diri. Oleh itu, harus diketahui bagaimana keyakinan diri dapat menentukan masa depan kerana pelajar perlu memperbaikinya dari hari ke hari. 
Seterusnya, penyesuaian intrapersonal melalui keyakinan diri. Motivasi diri dan keyakinan diri bukanlah perkara yang sama kerana keyakinan diri lebih merujuk kepada melihat konsep diri (The Life Virtue, 2019). Sebagai manusia, pelajar perlu lebih yakin dengan diri sendiri dan sentiasa berpegang pada kepercayaan dan pendapat ketika menganggap sesuatu perkara adalah benar. Pelajar tidak boleh membiarkan pendapat orang lain membuat menghakis keyakinan kecuali pendapat itu benar- benar membantu dalam mencari dan memberi penyelesaian bagi setiap permasalahan. Sebagai contoh, setiap kali pelajar menyampaikan idea di dalam kelas, pastikan untuk sentiasa yakin bahawa idea tersebut mempunyai kualiti sama dengan yang lain. Gerak hati ini merupakan kompas dalaman yang selalu berkomunikasi dengan diri. Kadang kala, mendengar apa yang dikatakan hati dapat menguatkan intrapersonal. Membina ikatan yang kuat dengan gerak hati dengan mempercayai intuisi walaupun pada perkara kecil dalam kehidupan, akan menguatkan jati diri dan menjadi lebih yakin pada diri sendiri.

Yang terakhir ialah menyesuaikan diri dengan universiti sebagai pelajar melalui kesedaran emosi. Kesedaran emosi ini penting kerana emosi yang tidak terkawal akan selalu merugikan diri dan orang di sekeliling ketika berada di dalam situasi atau kehidupan peribadi yang tidak dapat dikawal (Goleman, 2018). Tanpa mengira tindakan orang yang berada di sekitar, sesuatu masalah tidak akan menjadi serius tanpa mereaksi terhadap tindakan mereka. Akan tetapi tidak bermakna untuk tidak mengambil peduli dengan apa yang berlaku dalam situasi kehidupan. Emosi mempunyai peranan yang sangat kuat dan penting dalam hidup. Akan tetapi, jika dibiarkan, emosi akan mengawal dan menguasai diri dan seterusnya mengundang masalah. Oleh itu, emosi perlulah dijaga dan tidak membiarkan orang lain mengambil kesempatan dengan menyasarkan kelemahan emosi. Terdapat pelbagai perspektif, sikap, dan latar belakang yang berbeza berdasarkan individu, jadi, pelajar perlu berhati-hati dengan persekitaran (Doyle, 2019).

\section{Kemudahan Teknologi}

Di Malaysia, perkembangan teknologi semakin hari semakin berkembang maju. Pelbagai prasarana dan bangunan yang berteknologi tinggi telah pun dicipta oleh rakyat Malaysia. Kehidupan yang dulunya berasaskan teknologi tradisional kini semakin hari semakin beralih menuju ke arah permodenan dengan wujudnya alatan yang canggih menggantikan peralatan yang lama. Pembangunan ini selaras dengan matlamat negara menuju Revolusi Industri 4.0 (IR 4.0). Sehubungan dengan itu, rakyat Malaysia haruslah mengikuti arus perubahan ini dengan mengadaptasikan diri kepada teknologi yang semakin hari semakin menjadi keperluan hidup. Teknologi merupakan satu konsep yang mempunyai takrifan yang begitu luas dan ia merangkumi pelbagai aspek dalam kehidupan. Menurut Kamus Dewan Bahasa dan Pustaka edisi Kedua, teknologi merupakan ilmu tentang cara mencipta barang- barang dalam perusahaan seperti bangunan dan jentera. Jadi, teknologi ini boleh dikatakan sebagai alatan atau medium yang baru atau canggih dicipta untuk kegunaan masyarakat. Jadi, dengan adanya pembangunan teknologi ini, masyarakat perlu mengadaptasikan diri kepada teknologi- teknologi canggih agar tidak menjadi seperti katak di bawah tempurung. Justeru, memiliki kemahiran atau caracara untuk mengadaptasikan diri kepada dunia berteknologi adalah satu keperluan.

Antara kemahiran adaptasi kepada teknologi ialah melalui maklumat dan komunikasi. Sejak negara berkembang maju, bidang teknologi maklumat dan sistem komunikasi turut berkembang dengan adanya internet dan jalur lebar. Perkembangan ini amatlah penting untuk menyampaikan maklumat serta berkomunikasi dengan lebih cepat dan pantas dengan orang lain mahupun yang tinggal berjauhan. Terdapat juga pelbagai aplikasi untuk berkomunikasi dan bersosial seperti Facebook, WhatsApp, Instagram, dan sebagainya. Aplikasi ini digunakan secara meluas bukan sahaja di Malaysia, bahkan di seluruh dunia. Jadi, pelajar perlu mendedahkan diri dengan teknologi- teknologi ini agar dapat menyesuaikan diri dengan keadaan semasa. Tidak pernah menggunakan teknologi aplikasi ini tidak bererti tidak perlu mengambil tahu tentang teknologi ini. Sebaliknya, pelajar harus mempelajari dan cuba biasakan diri dengan penggunaan teknologi ini agar tidak ketinggalan zaman. Medium ini amat berguna dan banyak memberi manfaat kepada pelajar sekiranya dapat digunakan ke arah yang baik (Hamimi, 2018). Malah, penyebaran maklumat juga dapat dilakukan dengan mudah dan cepat. 
Selain itu, perkhidmatan dan kemudahan awam juga telah turut mengalami revolusi. Jika dilihat semasa negara belum mencapai Revolusi Industri 4.0, agak sukar bagi pelajar untuk mendapatkan servis perkhidmatan. Tetapi, teknologi hari ini telah memasuki setiap ruangan servis termasuklah servis perkidmatan. Penghasilan aplikasi perkhidmatan seperti pengangkutan awam menerusi aplikasi Grab telah memberi ruang dan membantu golongan yang tidak memiliki pengangkutan sendiri untuk bergerak (Linda, 2020). Sehubungan dengan itu, pelajar haruslah mengambil peluang ini untuk belajar cara- cara penggunaan aplikasi ini kerana ia memudahkan urusan rutin harian. Penggunaan perkhidmatan pengangkutan awam seperti Grab ini amat kerap diguna pakai oleh golongan muda lebih- lebih lagi golongan pelajar universiti kerana rata- rata antara mereka tidak memiliki kenderaan sendiri. Pelajar hanya perlu membuat tempahan melalui aplikasi Grab dan tunggu sehingga kereta sampai untuk membawa mereka ke lokasi yang ditetapkan dengan cepat. Selain aplikasi Grab, aplikasi seperti Uber dan Maxim juga menjadi tumpuan kerana aplikasi ini turut menyediakan perkhidmatan pengangkutan untuk bergerak. Jadi, amatlah rugi jika tidak dapat mengadaptasikan diri dengan persekitaran atas talian ini kerana teknologi ini mampu membantu dan memudah urusan.

Seterusnya, teknologi yang perlu diadaptasi ialah teknologi aplikasi panggilan video. Memandangkan musim wabak Covid-19 sedang merebak ditambah pula dengan Perintah Kawalan Pergerakan oleh kerajaan, sudah tentu tidak dapat melakukan aktiviti harian. Institusi pendidikan tidak mengira institusi pengajian tinggi mahupun rendah telah diarahkan supaya tidak melakukan sebarang aktiviti pembelajaran dalam kelas. Akan tetapi, pembelajaran harus diteruskan dengan mengambil inisiatif menggunakan aplikasi pembelajaran atas talian sebagai medium utama untuk meneruskan pembelajaran, pengajaran, perbincangan, dan lain-lain. Penggunaan aplikasi panggilan video seperti aplikasi Zoom, Webex, panggilan video melalui aplikasi WhatsApp, dan sebagainya telah menjadi wadah utama untuk sesi pembelajaran sekarang. Aplikasi ini lebih berkesan dan membantu para pelajar untuk belajar dengan mudah di rumah. Aplikasi ini juga boleh merakam sesi perbualan atau pembelajaran bersama tenaga pengajar. Sehubungan dengan itu, pelajar perlulah membiasakan diri dengan mengadaptasikan teknologi yang tersedia ini kerana teknologi ini amatlah berguna lebih- lebih lagi kepada golongan pelajar walaupun tidak bersemuka dengan tenaga pengajar.

\section{Kesimpulan}

Kesimpulannya, pelajar perlu mengingatkan diri bahawa ketenangan itu datang dari ketenangan hati dan juga fikiran agar dapat hidup di dunia dan tempat yang lebih baik. Pelajar juga harus mengambil kesempatan untuk mempelajari dan meningkatkan sifat interpersonal dengan mempunyai kemahiran berkomunikasi yang baik, dapat mengurus konflik, dan bersikap empati terhadap orang lain yang harus dimiliki setiap orang. Selain itu, sebagai masyarakat yang hidup dalam dunia revolusi industri yang mempunyai pelbagai teknologi yang canggih, pelajar mestilah mengikuti arus perubahan ini dengan mengadaptasikan diri dengan teknologi yang tersedia ini. Pengadaptasian diri kepada teknologi adalah amat penting kerana kehidupan sekarang penuh dikelilingi oleh teknologi. Dengan memiliki kemahiran ini, pelajar dapat menyesuaikan diri dengan mudah tanpa mengira keadaan sama ada masalah baru atau masalah yang pernah hadapi sebelum ini. Hasilnya, pelajar mempunyai banyak kemahiran insaniah yang akan membantu mempelajari dan mengatasi persekitaran baru di universiti sebagai pelajar dan di alam pekerjaan sebagai pekerja.

\section{Rujukan}

Doyle, A. (2019). Important Adaptability Skills for Workplace Success. 4 September 2019. The Balance Careers: Succeeding at Work. Sumber: https://www.thebalancecareers.com/importantadaptability-skills-4768260

Futuristik HAI-O Bulletin (Bil. 27). Penggunaan Teknologi Dalam Perniagaan. 3 April 2013. Idzulsyahril: Langkah di Persada. Sumber: https://idzulsyahril.wordpress.com/2013/04/03/penggunaan-teknologi-dalam-perniagaan/ 
Goleman, D. \& Boyatzis, R.E. (2017). Article Emotional Intelligence: Emotional Intelligence Has 12 Elements. Which Do You Need to Work On? 6 Februari 2017. Harvard Business Review. Sumber: https://hbr.org/2017/02/emotional-intelligence-has-12-elements-which-do-you-need-to-work-on

Linda (2020). Cara Menggunakan Aplikasi Grab Paling Mudah dan Praktis. 27 Mac 2020. Carisinyal. Sumber: https://carisinyal.com/cara-pesan-grabcar/

Lolli, J. C. (2013). Interpersonal Communication Skills and the Young Hospitality Leader: Are They Prepared? International Journal of Hospitality Management, 32(16): 295-298.

Main, A., Walle, E.A., \& Kho, C. (2017). The Interpersonal Functions of Empathy: A Relational Perspective. Emotion Review, 9(4): 358-366.

Nurul Hamimi Awang Japilan (2018). 3 Kemahiran Yang Perlu Dikuasai Pelajar Abad ke 21. 30 April 2018. Blog Ustazah Hamimi. Sumber: http://ustazahamimi.blogspot.com/2018/04/3kemahiran-yang-perlu-dikuasai-pelajar.html.

Tang, S.F.Y \& Kirkbride, P.S. (1986). Developing Conflict Management Skills in Hong Kong: An Analysis of Some Cross-Cultural Implications. Management Learning: Management Education and Development, 17(3): 287-301.

TheLifeVirtue (2019). Intrapersonal Skills \& Intelligence - The Ultimate Guide 2019. 26 Mei 2019. The Life Virtue. Sumber: https://thelifevirtue.com/intrapersonal-skills-intelligence/

Wang, N. \& Wu, G. (2020). A Systematic Approach to Effective Conflict Management for Program. SAGE Open, 1-15. 